\title{
Improving Five Grade Government Girls Primary School Students Reading Comprehension Skills in Sindh Pakistan
}

\author{
Leena ahmed \\ Supervisor ( Syed Waqar Ali Shah) \\ Ms Student Eldc \\ Mehran Uni Jamsoro \\ Sindh Jamshoro Pakistan
}

\begin{abstract}
The design of this study was a quasi-experimental study. The study was conducted in GGPS Gul Mohmmad Parhyar. The population of this study included all the fifth grade students of GGPS Gul Mohmmad Parhyar in the academic year of 2019/2020. Two classes were selected from the population as the experimental and control groups, i.e. Class V A and Class V B. There were 15 students in Class A and 15 students in Class B. Class A was chosen as the experimental group while Class B was chosen as the control group. The experimental group was taught by using strategic reading-SQ3R whereas the control group was taught by using non-strategic readingSQ3R. The data were collected by administering a pre-test and a post-test. The data were analyzed using independent $\mathrm{P}$ test.The results of the data analysis are as follows. First, the mean score of the post-test in the experimental group (29.67) is higher than that in the control group (27.33). Second, there is a significant difference in the reading comprehension ability between both groups indicated by the results, in which the significance level is $5 \%$ or 0.05 and $p$ value 0.000 which is less then 0.05 . Therefore, our result give the evidence in favor of research hypothesis that is"There is a significant difference in the reading comprehension ability between the 5th grade students GGps Gul Mohmmad Parhyar in the academic year of 2019-20.
\end{abstract}

Keywords: SQ3R (Survey, Question, Read, Recall, Review).

DOI: $10.7176 /$ RHSS/11-4-03

Publication date: February $28^{\text {th }} 2021$

\section{Introduction}

English is an international language and serves as a global language in the world which is why English competency is very important for the students to progress further. When it comes to English, Reading is one of the most important skills of the basic skill set. We learn from the literature that we get to have command on four skills in order to learn a language.

Reading in the field of education holds great importance, not only in the discipline of English but mostly in all language-based courses. A student will not be able to comprehend the content written in the books unless his or her reading skills are sharp. The problem lies in the difficulty comprehending the reading material in some schools, colleges and universities. Like many other countries in the world, Pakistan also aspires to be a recognized country on the globe and when it comes to recognition, one of the most important factors is language learning, understanding and communicating.

In real situation in government schools reading comprehension skills of students level is blow the standard; the other major reason is, teachers are not using different techniques in teaching reading comprehension more over students are having difficulty in English specially reading..In order to develop students ${ }^{\text {ee }}$ intellectual thinking and improve their reading comprehension skills, SQ3R strategy which stands for Survey, Question, Read, Recall and Review can be introduced. SQ3R is a well-liked reading strategy. SQ3R strategy not only enables students improve their reading skills but also makes the reading process less difficult and more interesting 
Table: Components SQ3R Describe

\begin{tabular}{|l|l|l|}
\hline Component & Process & Goal \\
\hline Survey & $\begin{array}{l}\text { Skim through the text and try to form an idea as to what the } \\
\text { text is about. }\end{array}$ & $\begin{array}{l}\text { Find a reason to read the } \\
\text { passage }\end{array}$ \\
\hline Question & $\begin{array}{l}\text { Turn the main heading into question, and generate more } \\
\text { questions from the first few lines of the passage. Find answers } \\
\text { of these questions when you read through the passage. }\end{array}$ & $\begin{array}{l}\text { Create interest in the reading } \\
\text { material }\end{array}$ \\
\hline Read & $\begin{array}{l}\text { Read the material thoroughly, and cautiously for you have to } \\
\text { find answers to the questions in your head. }\end{array}$ & $\begin{array}{l}\text { Utilize the interest you } \\
\text { generated for a careful read. }\end{array}$ \\
\hline Recite & $\begin{array}{l}\text { Map everything what you read and now tell this to someone or } \\
\text { to yourself point by point in your own words. }\end{array}$ & Summarize the information. \\
\hline Review & Read again to strengthen the concept(s). & $\begin{array}{l}\text { Assimilate information in a } \\
\text { larger picture; use mnemonic } \\
\text { techniques }\end{array}$ \\
\hline
\end{tabular}

Taken from Brown (1992) \& Huber (2004)

\section{Research questions}

- Q1How do students use the SQ3R reading strategy in improving their reading comprehension?

- Q2. What are the opinions of students about this intervention in improving reading comprehension?

- Q3. What is the difference between students reading comprehension test score before during and after intervention

\section{Literature Review}

SQ3R is a reading comprehension strategy devised for reading textbook and assignments for diverse learners. It develops an intrusive, dynamic attitude towards learning and doubles the cognitive processes of successful learners. Robinson devised this strategy in early 1940s (Robinson, 1941). It was also named as „the grandfather of study strategies" (Lipson \& Wixson, 2003).

SQ3R stands for five steps that the students follow in using this method. They are Survey, Question, Read, Recite and Review.

Step1 is survey where the students get information by skimming the title of the reading text, the introduction, illustrations, pictures and captions. They then underline new words, and guess their meanings. In case of many paragraphs, students try to skim the heading and extract main points, which are subsequently developed. (Robinson, 1941) as students only look for headings. Robinson views that "surveying" the text prior to reading leads students towards better understating of main idea..

Step2 is question. Robinson (1941) advocates the use of questioning by citing Washburn"s and Holmes ${ }^{\text {ee }}$ work (as cited in Robinson). Students change the topic headings into a question. Even for getting more meaningful ideas they can convert the first sentence of the paragraph in question as well. Questioning is a process to know the unknown. The more they question the more they will know. Robinson asserted, "This will arouse your curiosity and so increase comprehension" (p. 29). Thus questions deepen students" curiosity and they extract main points. Making a question needs sensible attempts on the part of the students even though they can convert a heading into a question very easily.

Step 3 is reading where students try to find out the answers to the question they have made in the preceding step. Robinson (1941) describes the reading portion of SQ3R as "an active search for the answer" (p. 29). Finding answers to the questions should not be a dull and passive activity rather it should involve active cognition. Noting and underlining the new words, and using dictionaries for blocking items are just a few steps. The students should have the purpose of reading in their minds as they read each section rather running their eyes passively on each line.

Step 4 is to recite what has been read. The reader should not scan or read through the text to find the appropriate answers (Robinson, 1941). After reading, students close books and try to repeat and revise the answers to the questions in their own words. Students can skim again and repeat what they have recited. The reader should take brief notes with headings and subheadings while reading (Robinson, 1941). Writing down ideas, phrases and making notes is the best method to recite from memory. The Q, R-1, and R-2 should be repeated with each heading until the selection has been completely read (Robinson). This process can be repeated with the rest of headings and paragraphs till the entire chapter is completed. The final step of the SQ3R method or

step 5 is review (R-3), and is justified by Spitzer"s work supporting the technique (as cited in Robinson, 1941). After the completion of step 4, students can review their notes by looking at the main points and their relationship to each other. Then they can test their memory by reciting the main points and the sub points 
under

\section{Materials and Methods}

This study has been designed as a quantitative action research study. Action research is a circular process of identifying and solving classroom or school problems while working collaboratively with various partners .

In this study, reading comprehension problems among five grade primary school students were considered. Within this scope, students' reading and comprehension levels were measured and it was clearly determined that these students reading comprehension skills were below standard. According to Güneş [41], primary school $5^{\text {th }}$ grade students should be capable of reading 90 to 140 words per minute. Thus, in order to improve their reading comprehension skills an action research plan was prepared

\section{Sampling}

In this study, "criterion sampling", one of the purposeful Sampling methods was utilized for the sampling. primary school 5thgrade students of GGPS GUL MOHMMAD PARHYAR two sections has been selected 5th A and 5th B both contains 15 students each section A represents control group and section 5th B represents experimental group

\section{Data Collection Tools}

The study tool in this research is a reading comprehension evaluation. The evaluation comprises two assessments - pre and post activity assessments. These assessments are based on multiple choice questions or MCQs, in which the students are usually asked question about the genre of the passage of reading, i.e., recount and narrative texts. These assessments were designed to evaluate student's reading comprehension skills before and after the treatment with reading strategy - SQ3R. As the name suggests, the pre evaluations were carried out ahead of the treatment and the post assessment after it

\section{Data analysis}

There were two data analysis techniques used in this research. They were the descriptive and inferential analysis. Descriptive analysis is aimed to describe the result scores of the students' reading comprehension in each group, while inferential analysis is to answer the question of the formulation of the problem, which is whether or not strategic reading-SQ3R is effective to improve the students' reading comprehension ability.

\subsection{DESCRIPTIVE ANALYSIS}

Descriptive analysis was aimed to describe the result scores of the students' reading comprehension in each group. The statistics used were mean and standard deviation.

To analyze the data descriptively, the researcher made score categorization of the students' reading comprehension ability first.. The categorization of the students' reading comprehension score was based on the ideal score. The highest score was 40 and the lowest score was 0 . The ideal mean score (Mi) and ideal standard deviation (SDi).

The frequency distribution of the students' reading comprehension ability scores can be categorized into six levels; excellent, very good, good, fair, poor,and very poor. The distribution was calculated based on the Mi score and SDi. The categorization of the students' reading comprehension ability is presented in the following table.

Table: The Students' Reading Comprehension Ability Score Category

\begin{tabular}{|l|l|}
\hline Interval & Category \\
\hline $40-34$ & Excellent \\
\hline $33-27$ & Very Good \\
\hline $26-20$ & Good \\
\hline $19-13$ & Fair \\
\hline $12-6$ & Poor \\
\hline 5 and less than 5 & Very Poor \\
\hline
\end{tabular}

\subsection{INFERENTIAL ANALYSIS}

The inferential analysis is aimed to answer the question of the formulation of the problem, which is whether or not strategic reading is effective to improve the students' reading comprehension ability. To fulfill the requirement for the hypothesis testing, the tests of normality and homogeneity are employed.

a. Normality Test

The test of normality is used to see whether or not the data analyzed meet the requirement of a normal 
distribution. This test was done by using the SPSS 26.0 for windows computer program of distribution normality test. The Kolmogorov-Smirnov test is employed in testing the distribution of normality.

\section{b. Homogeneity Test}

The homogeneity test is aimed to know whether or not the score variances in the groups are homogeneous. To test the homogeneity, the Levene test was employed. This test was done by using the SPSS26.0 for windows computer program of homogeneity test.

\section{c. The independent t-test,}

also called the two sample t-test, independent-samples t-test or student's t-test, is an inferential statistical test that determines whether there is a statistically significant difference between the means in two unrelated groups.

Suggestions and conclusion

This study showed that the SQ3R-based reading program increased students' reading comprehension skills. In the light of data obtained from this study, it can be seen that students' skills in analyzing visual information, predicting textual content and note-taking improved. Additionally, their number-of-words-read per minute and word-recognition percentages improved considerably. All in all, it can be clearly seen that the SQ3R strategy contributed both to students' reading and comprehension skills. Indeed, previous studies about theSQ3R strategy have also come to similar conclusions [42-43-44].

Butler [32] carried out a similar study in high school biology lessons. Students were divided into two groups, experimental and control. The experimental group took the lesson with the SQ3R strategy. Their academic success and attitudes towards the lessons were found to be better than those of the control group, which is in line with the positive impact found in our study. Also, Fisher [33] used this strategy with social Science textbooks in order to provide more meaningful learning and his study also found SQ3R very helpful for reading and comprehending the texts.

Hours a day for 05 days each week and it was implemented for 04 weeks. The researcher carried out this intervention with the classroom students

\section{References}

Dechant. (1982). Improving the Teaching of Reading: third edition. USA: Prentice Hall.

Grabe, William. 2009. Reading in a Second Language (Moving from Theory to Practice. United States of America. Cambridge University Press.

Mertle, A Craig, (2009). Action Research Teacher As Researcher In The Classroom.

America : United Stated of America.

Baier, Kylie. 2011. The Effects of SQ3R on Fifth Grade Students' Comprehension Levels. Bowling Green State University.

Aditya, R. (2014). Improving the eighth grade students' reading skill through SQ3R technique in SMPN 1Jongonlan in academic year 2013/2014. (Doctoral dissertation, the University of Negeri, Yogyakarta. Indonesia). Retrieved from http://www.nsta.org/publications/news/story.aspx? id=52391.

Anggita, A. (2018). Improving the eighth grade students' reading comprehension through SQ3R technique in MTs $N 1$ Bandar Lampung in academic year 2017/2018. (Doctoral dissertation, the University of Raden Intan State Islamic, Lampung. Indonesia). Retrieved from http://educationnorthwest.org/webfm_send/134

Baier, K. (2011). The effect of SQ3R on fifth grade students comprehension's levels. Ohio: Bowling Green State University.

Bushel, (2011). Classroom strategies for interactive learning. Newyork: International Reading Association, Inc. 